\title{
Transformation in the wholesale and retail sector in South Africa: the role of internships
}

\author{
Siphokazi Koyana \\ Roger B Mason \\ Cape Peninsula University of Technology, \\ Cape Town, South Africa
}

Keywords

Intern; Retail; South Africa; Graduate placement; Career advancement; Skills development

\begin{abstract}
This paper presents an investigation into internships in South Africa's retail sector. The research questions it seeks to answer are: (i) What are the benefits (strengths) of this sector-sponsored internship programme (ii) What are its limitations (weaknesses), and (iii) What changes, if any, can be recommended to improve the programme? The methodology used was a case study of a retail sector internship, with data gathered via a survey of 12 retail firms, two focus groups of 15 interns, and four depth interviews with retail managers who had previously been interns. The study found that the programme is very beneficial to the participants, as they get exposure to real work opportunities and the previously disadvantaged are empowered with requisite skills for the sector, assisting with career advancement and upward mobility. This was despite the weaknesses of an inadequate stipend for interns and inefficiencies in the internship administration.

This paper has confirmed that the retail internship is achieving the expected benefits, but highlights some critical aspects needed for future success. Further, it has provided knowledge in an under-researched area, namely internships in the retail sector. These findings could be beneficial for other sectors.
\end{abstract}

Corresponding author: Roger B Mason

Email addresses for corresponding author:masonr@cput.ac.za

First submission received: $9^{\text {th }}$ November 2017

Revised submission received: $30^{\text {th }}$ January 2018

Accepted: $16^{\text {th }}$ March 2018

\section{Introduction}

South Africa's National Development Plan (NDP) shows that three million people between 18 and 24 years old, many who are graduates, were not in employment, education or training (Republic of South Africa, 2011), this despite the skills shortage in the retail sector. Employers maintain that students lack the practical experience and the skills needed in the workplace (Blom, 2013) and are therefore unable to use these graduates to fill their vacancies (Republic of South Africa, 2013). According to Blom (2013), universities produce the wrong type of graduates. Finding ways of increasing the employability of the youth is therefore a major priority.

In South Africa, internship programmes (other than the long established medical internships) are relatively new. They were included as a new entrant category into the NDP and are operationalised by the Department of Higher Education and Training, which oversees the Sector Education and Training Authorities (SETAs) that have established internships in the various occupational sectors (Pop \& Barkhuizen, 2010). Due to the potential for internships to create jobs and reduce crime rates (Mabiza et al., 2017), and to the importance of retail to the South African economy (Sewell et al. 2014), it will be worthwhile to assess the success of such SETA funded internships. Therefore, this paper, after reviewing relevant international and South African literature, will explain, as a case study, the internship developed and offered by the Wholesale and Retail SETA (W\&RSETA) and present the findings of an essentially qualitative examination of the success of this programme as well as some of its weaknesses. Finally, implications of the programme and recommendations for improvement will be provided. Although focused on the retail sector, we believe the findings and recommendations will also be useful for other SETAs offering internships. 


\section{Literature review}

\subsection{Benefits of internships to the student}

Many benefits are derived from internships. These include the opportunity they provide interns to participate in a realistic job experience (Jackson 2015). Internships furnish interns with opportunities to work with professionals in their field, and to develop networks with potential mentors who can provide references and future job positions (Burns \& Chopra 2017). As colleges and universities can only do so much to provide the skills development needed for today's workplace, internships provide practical experience wherein interns learn by observing and applying the methods and theories learnt in the classroom. Interns are exposed to up-to-date equipment and facilities that are often not available in most types of educational institutions. This also enables them to apply classroom theories in real-world scenarios, thus augmenting and complementing their classroom learning. These mechanisms are invaluable for developing sector-specific workplace skills (Guille \& Lahiff 2013).

Improvements in personal (i.e. discipline-related knowledge), interpersonal (i.e. communication skills), civic (i.e. cultural competence and social responsibility), and professional (i.e. career interests) developments have been observed among those who have participated in internships (Simons et al 2012). Interns also acquire valuable skills such as collaborative and creative processes, consulting, teamwork, self-esteem, and motivation development (Green 2012). In addition to developing their non-technical skills, interns may improve their understanding of ethical behaviour and professional conduct (Smith and Worsfold 2014).

Moreover, recent research proves that internships also build a higher level of resilience for the participants. In a study using psychometric testing to reveal the benefits of university internship placements, Goodenough et al (2017) showed that the internship experience increased the individual's capacity to create, to make the most of opportunities, and to respond positively to setbacks or challenges. Increased resilience was shown to have direct correlations with higher attainment, retention, engagement, and employability. Furthermore, in the UK, evidence suggests that more than $33 \%$ of all graduate vacancies are taken by those who have already had an internship or other work experience in that company (High Flyers 2014). As such, internships are generally accepted as a useful mechanism for facilitating the student's transition from higher education to employment (Jackson 2015).

Notwithstanding the overall value of internships as mentioned above, the benefits of unpaid internships have come under scrutiny over the past few years. Aspiring interns participate in unpaid internships for the sake of getting practical exposure to the workplace, to develop a reputation in their chosen fields, and to network with professionals who might help them secure permanent work (Guile 2009). However, more recent findings suggest such unpaid internships provide less mentoring, less development, low task goal clarity and less autonomy. These are all factors which reveal a higher potential for intern neglect than do paid internships (Jackson 2017). Frenette (2013) concurs that the management of unpaid interns is often less formal, more opportunistic and therefore deficient in the setting of performance standards and the provision of feedback. Consequently, unpaid interns tend to not only feel exploited but also report lower satisfaction than paid interns (Siebert \& Wilson 2013). In the job market, unpaid interns are presumed to have low status and to lack valuable skills, which results in them receiving fewer job offers and lower starting salaries than their counterparts do (NACE 2013, in McHugh 2017). Moreover, unpaid internships further disadvantage graduates from low economic classes, as they often cannot pay for transport, accommodation, childcare, etc. (Klein \& Weiss 2011). It therefore comes as no surprise that unpaid interns filed more than 30 lawsuits against their employers in the USA between 2011 and 2014, as more people challenge the ethics, justice, and legality of such internships (Suen \& Brandeisky 2014).

\subsection{Benefits of internships to the employer}

For the employer, interns represent a potentially viable pool of new employees, as the internship enables the company to assess students' work capabilities before extending offers for full-employment (Govender \& Taylor 2015). In other words, employers use the internship as a recruitment tool, as it offers the employer a good opportunity to entice prospective employees and to get a better idea of the intern's suitability and ability to adapt to the organisation's culture than in an interview ( $\mathrm{O}^{\prime}$ Connor \& Bodicoat 2017). Employers can use interns for completing delayed or shelved projects and for the professional 
development of staff who are less experienced in supervising and mentoring. Supervising interns enhances promotion opportunities for junior and middle management staff as it demonstrates leadership skills (Jackson 2017).

Moreover, employers utilise interns as a cost savings measure, as compensation for paid internships is generally less than for entry-level positions. In the case of unpaid internships, the employers' benefits are even more obvious, as employers gain the usage of human capital at only the cost of training (Meinert 2013). The benefits of paid internships to the employer are that they enhance the employer's ability to retain top interns to fill full-time positions. Furthermore, paid internships may help improve the value of the employer's brand, as interns will give their families and friends a favourable impression of the employer. This may add to the employer's status and improve the organisation's reputation among potential job applicants in the broader job market (McHugh 2017). Worth noting is that a good employer should focus on long term benefits, such as, improving the talent pool available for graduate recruitment within the industry rather than "quick fix" placements to fill a gap in operational activities for a short period of time (Jackson 2017).

On the other hand, factors that may hinder employers from offering internship opportunities include not knowing how to get suitable interns, not having sufficient work for suitable interns, and not having the infrastructural and financial resources for providing and administering an internship programme (a problem more common to small than big enterprises). Those employers who acknowledge that the lack of skilled, dedicated personnel necessary to supervise and mentor interns is a barrier to their provision of internships aptly recognise that the lack of adequate supervision can be damaging for their brands and cause frustration and anxiety for interns (Jackson 2017).

\subsection{Characteristics of good internships}

The USA has a preponderance of research on characteristics that make a good quality internship programme. The most commonly noted are compensation, job characteristics, and supervisor support (McHugh 2017). These observations are supported by Guile and Lahiff (2013), who posit that best practices for internships include transparent recruitment processes, payment for interns, agreed learning goals, and the chance for interns to work with multi-skilled teams to meet the needs of clients. This helps them develop judgment, entrepreneurialism, and other skills specific to the sector. These researchers also found that internships often work best with a mix of formal and informal arrangements for induction. The interns should be involved in a mix of observation and shadowing, as well as individual and collective responsibility for work.

The optimal job characteristics include not only the alignment of the job with the intern's qualifications and career goals (e.g. placing a buying intern at the retailer's headquarters), but also assigning interns meaningful, challenging, yet achievable tasks, involving them in planning projects, soliciting their ideas and opinions, and holding them accountable for projects and deadlines. Such activities indicate the supervisor's respect for, and trust in, the intern's capabilities (Hurst et al. 2012). Moreover, the opportunity to influence the way work is done has been found to positively influence workplace learning (Virtanen et al. 2014).

The importance of the role of a good supervisor in a quality internship cannot be overemphasised. Good supervisor support is critical as it defines lines of authority, helps inculcate positive work habits, and enhances the overall experience for the intern. It is necessary to provide interns with supervisors or mentors who can provide the required feedback, guidance, training, and share information about the process of permanent hire considerations quite early on (Hurst et al. 2011). Good supervision is so integral to the intern's skills and career development that it leads to higher job satisfaction for both paid and unpaid interns (McHugh 2017).

\subsection{Mandatory versus optional internships}

In addition to highlighting the dichotomy between paid and unpaid internships, another critical debate among internship researchers is the difference between mandatory and optional internship programmes. On the one hand, a German study found compulsory internships implemented in higher education curricula to have no beneficial effects on labour market outcomes, i.e. on the duration of the job search process, on hourly wages five years after graduation and on the stability or "complexity" of the 
employment career (Klein \& Weiss 2011). Complexity of employment history in the first five years refers to the quality of the match between job and applicant. Graduates often do not get the most suitable jobs as they might lack critical information on the employer and on the job (Wolbers 2003). As a result, employment might be followed by periods of unemployment. Furthermore, there were no benefits for students from lower educational backgrounds. Because such students often lack the parental social resources and networks that enable their middle class and higher educational counterparts better access, it has been strongly believed that internships are strongly beneficial to them (O'Connor \& Bodicoat 2017). Klein and Weiss' (2011) findings clearly debunk that notion by revealing that students lack motivation when forced to take an internship. As a result, they do not make the most of the opportunities available for enhancing their occupation-specific work skills during their internship. These findings thus concur with those of O'Connor and Bodicoat (2017), who assert that optional internships have beneficial effects because the students who take them self-select, i.e., they have high abilities and already demonstrate stronger motivation and higher career salience than their counterparts do. These attributes enable them to gain sufficient job-specific knowledge and access to additional resources.

In contrast to the above, Silva et al. (2016) prove that in Portugal, which at $30 \%$ had one of the highest unemployment rates in the European Union in 2013, mandatory internships have significantly reduced graduate unemployment, thus suggesting that mandatory internships may be beneficial for graduates of both universities and polytechnic institutions. These researchers suggest that employers tend to view graduates who have not undergone the mandatory internship as not being committed to learning on the job. The variation in findings between Germany and Portugal clearly underscores that the effectiveness of mandatory internships depends on the particular country's processes at labour market entry or on its settings of the education-labour market design.

\subsection{Internships in South Africa}

Very little research into internship programmes has been published in South Africa and none in the retail sector that we could find. Examples of extant research are a Department of Science and Technology youth programme (Grayson, 2012), internships as a talent retention strategy in IT (Pop, 2010; Pop \& Barkhuizen, 2013), and a programme for sports management personnel, which found both a professional and a personal level of benefit, improving the interns' potential for career advancement (Surujlal \& Singh, 2009). Buhlungu \& Metcalfe (2001) studied an internship in a Sociology of Work Unit (SWOP) at the University of the Witwatersrand, finding that black intellectuals developed as professionals when they were supported through an internship programme. A nationwide baseline study focussing on internships offered by three government entities found the programmes had helped participants realise that they were competent and employable (Koyana 2013). Although having different contextual bases, all these studies come to a common conclusion that internships produce a more accomplished worker with higher employability and retention potential.

\subsection{Conclusion to literature review}

In conclusion, what we know about internships is that they provide very valuable experiential workplace learning for interns and help them envision their future careers. They have also become an acceptable recruitment tool for employers, helping ease the graduates' transition from the classroom to the workplace. There is also strong evidence that paid internships provide better developmental value, more job pursuit intensions and higher internship satisfaction. As to whether compulsory or mandatory internships offer better benefits, it is clear that success in either case is context specific. Although there is a reasonable amount of research in developed nations, as shown above there is no research on internships in the retail industry in South Africa, a developing nation. The importance of the retail industry is shown by the fact that it accounts for about 15\% of GDP (South African Market Insights 2015) and for about 21\% of employment (W\&RSETA, 2014). Therefore, gaining a better understanding of internships in this sector is essential for skills development and transformation. This gap in knowledge in the context of developing nations (and especially South Africa) will be addressed via an examination of a case study in the South African retail sector.

\section{A South African internship case study}


In South Africa, the internship programmes that were initially established by the Department of Labour now fall under the Department of Higher Education and Training and are funded through the Sector Education and Training Authorities (SETAs) (Pop \& Barkhuizen, 2010). SETAs are organisations that ensure skills training of good quality happens in each specific sector of the economy, e.g. health, construction, or mining sector. The Wholesale and Retail SETA (W\&RSETA) was established in 2000, and like other SETAs, is a legal statutory body and an accounting authority which receives money gathered from employers in its sector and then pays the money as a grant to employers to employ unemployed people for internships (iEducation SETA South Africa, n.d.). It is believed workplace exposure enhances the interns' chances of future appointment, as it allows them to apply their theoretical knowledge in practice and it also builds the necessary set of work behaviours, such as responsibility, honesty, productivity, etc.

The objectives of W\&RSETA's internship programme are to provide unemployed graduates with valuable work experience and skills, commensurate with their qualifications, to enhance their employability; to promote Wholesale and Retail (W\&R) as a career of choice in an effort to professionalise the sector; and to enable companies to address the scarce skills in the W\&R sector. The internship programme does not lead to a formal qualification but culminates in a testimonial letter indicating the work areas to which the graduate was exposed (W\&RSETA 2012)

Companies can source graduates with a W\&R related qualification from any of the public Higher Education Institutions by advertising on the companies' notice boards, their websites, or by word-ofmouth. The SETA provides participating graduates with a monthly stipend of R3,500 (\$220) for a graduate with a degree or diploma for a period of 12 months, or R3,000 (\$192) for a graduate from a Further Education and Training institution (Rand/dollar exchange rate on 1 March 2016 was R15.60/\$1.00). The graduates should have qualifications that address the scarce skills as per the Sector Skills Plan (SSP) published on the SETA's website (W\&RSETA, 2016). These include Retail Business Management, Food Technology, Supply Chain Management, Logistics Management, Financial Accounting, Financial Management, or Operations Management.

To demonstrate their capacity to implement the internship programme, host employers should not recruit interns to replace permanent, temporary or contracted employees. Employers should be able to commit to hosting interns for a year while developing and addressing the needs of the company. They should also conduct an induction programme and performance reviews to integrate the graduates into their company's culture as much as possible. Whilst the programme focuses on providing practical work experience, employers can provide further training if they find it necessary (W\&RSETA, 2016).

Therefore, considering the above literature showing the importance of internships and the fact that no published research is available regarding the South African retail sector, this investigation aims to contribute to new knowledge by focussing on a group of "self-selected," paid interns in a voluntary programme to answer the following research questions:

- What are the benefits (strengths) of this sector-sponsored internship programme?

- What are its limitations (weaknesses)?

- What changes, if any, can be recommended to improve the programme?

\section{Methodology}

This exploratory investigation sought to delve into a previously under-researched area, namely how the government funded retail internships contribute to the increased participation and career progression of retail graduates in South Africa. We therefore sought to assess how skills development, in the form of internships, could contribute to transformation and professionalization in the sector by examining, as a case study, the W\&RSETA's internship programme.

To provide a quantitative measurement, contact details of host employers were obtained from the W\&RSETA's head office. Thirty-eight host employers in Gauteng, Kwa-Zulu Natal, and Western Cape provinces were then identified and sent introductory emails and later survey questions to ascertain the number of interns they had hosted over the past ten years and how many they had absorbed at the end of their tenures. These were followed up with multiple telephonic and email reminders over a period of four weeks. At the end, 12 companies responded, implying a 32\% response rate. The figures we collated were submitted by host companies that vary in size, national footprint, ownership, and trade categories. 
To provide a qualitative measurement a carefully designed short questionnaire consisting mainly of open-ended questions was developed and used to guide the two focus group discussions composed of a total of 15 interns in Gauteng province, which is the most economically active of the country's nine provinces. Four interns were in a large wholesale store with more than 2500 employees working on the premises. The 11 remaining interns were from an initial cohort of 50 at the head office of a smaller retail group. A total of nine African females and six males (three African and three Coloured) participated in the two focus groups. Nine out of the 15 interns were former recipients of W\&RSETA bursaries for qualifications in retail-related disciplines. All interns were in the 2015-2016 financial year cohort.

To begin an exploration of progression and the long-term effects of internships, we subsequently held in-depth interviews with four young male black managers who had previously participated in the SETA's internship programme. The questions they were asked pertained specifically to the extent to which they felt the internship had influenced their career progress and to the specific areas in which they thought that they had grown because of the internship. The objective was to solicit their perceived value of the internship programme and to understand the trajectory of their career progression thereafter.

\section{Findings}

\subsection{Benefits of the programme}

Eighty percent (12/15) of the participants believed the internship had provided them with relevant work experience in their respective disciplines. Theory merged with practice as they started using IT programmes that are relevant for their business units. In fact, they felt they had learnt much more in the workplace than they had learnt from the theory provided in class.

About $75 \%(11 / 15)$ felt the mentoring provided by their supervisors, who transferred knowledge to them individually or during staff meetings, had been very constructive. They were affirmed when some supervisors implemented their recommendations or strategies they had devised. They also acknowledged that they had learnt tremendously from supportive co-workers when they sought assistance.

While most of the participants worked in only one department, a third (5/15) had been rotated and exposed to different departments within the organisation. For instance, a Human Resources graduate was forced to do inventory. While very apprehensive about this at first, he ended up enjoying inventory work and was applying for jobs in that field as the internship was nearing the end. Similarly, another intern was forced to do some financial work even though she had never studied finance before. She subsequently had to learn to ask for help and to figure things out as she was going along. As the internship was nearing the end, she was offered a year-long contract in a financial department, where she will receive proper training in that area of work. Had she not been rotated to the finance department, she would not have even considered applying for a job in that department.

In addition to enhancing their technical skills, all the interns agreed that the internship established essential workplace skills, such as, business communication (presentations, reports, minutes, emails), negotiation, decision-making, problem-solving, telephone etiquette, and interview skills. All the interns agree that they learnt to work under pressure as they had heavy workloads and/or long hours. Related to that is they also learnt the importance of time management and good customer service. The interns also learnt to work independently (without supervision). Those in the Human Resources department learnt to keep confidential information safe and to be very careful and accountable for other people's money, e.g. when processing payments, salaries, or claims. All of them also learnt the importance of optimally managing their personal budgets, e.g. paying their rent on time, minimising transport costs, and/or contributing to their families' needs.

The value of developing self-confidence cannot be over-emphasised. One intern related how, for fear of saying the wrong thing, early in her internship she would let the phone ring until it stopped if her supervisor was not in the office. Another, an IT graduate, mentioned how visibly her hands would shake when she was fixing her manager's computer. For many graduates who come from the racially segregated black townships, the internship provided their first experience of constant proximity and communication with white people. Therefore, suppressing one's anxieties and learning to nurture professional relationships or to make friends across racial and gender lines while demonstrating one's competence are some of the remarkable opportunities provided by the internship programme. Beyond learning how to perform better and more efficiently on a job, interns had thus also acquired cultural codes and specific 
manners that are expected in the social environment of the retail sector. Some of these skills were not communicated in the educational system or in the home environment and had to be experienced on the job.

In the process of offering interns realistic learning opportunities, the internship also helped them to manage their expectations of career progression. While many had assumed it would take only about two years after graduation to become managers, they now realised that it takes an average of five years or longer. Starting from the bottom and learning the responsibilities of building trust between the staff and management, being the custodian of the organisational culture, and ensuring compliance with all the government regulations for the retail sector takes more than the interns had initially assumed.

All emphasised that they would not know half of what they know now about the workplace and their own career aspirations if they had not been in the internship. Moreover, all concurred that they were aiming higher than when they arrived not knowing anything about work. Twenty percent of the participants $(3 / 15)$ wished to study further and obtain master's or even Doctoral degrees. Forty percent $(6 / 15)$ wished to have their own businesses in five years.

\subsection{Limitations of the programme}

A challenge expressed by the interns was that the workload was too heavy and the hours too long for the small stipend that they earned. The monthly stipend of R3, $500(\$ 220)$ has not changed since 2008 and thus fails to factor in inflation and the needs of millennials, such as airtime and data for digital communication needed for job searches. These commodities, though essential, are very expensive in South Africa. While interns were contractually supposed to work eight hours per day and half-days on weekends, it was not unusual for them to work 10-12 hours per day and to work the entire weekend or even on Public Holidays. Working after $20 \mathrm{~h} 00$ is a major inconvenience, as mini-bus taxis stop running at that time. It is dangerous for women who live far from work to be travelling back into the townships by themselves late at night. Furthermore, while the male interns could blatantly refuse to do additional work, the females were often too shy to refuse. Consequently, the little pay, long hours, and poor working conditions made it difficult for some interns to aspire for careers in retail, as they found this sector to be exploitative. For instance, some permanent staff at the head office earned R10 000 (\$640) per month after 10 years on the job.

Whereas most permanent employees were supportive of the interns, some were unwelcoming and would not answer the interns' questions. Such employees feared the interns had come to take their jobs. In addition, the provision of mentoring was generally inconsistent. Some managers generously imparted their knowledge and skills, while others could not care less about interns' personal and professional development needs, if they worked like slaves.

In the smaller retail group, where the host employer took in more interns than the available positions, interns were forced to perform demeaning manual labour such as cleaning toilets or washing trolleys. "My heart used to be very sore when I was going to work knowing that I was going to wash trolleys the whole day. There are so many people who didn't go to school who could do that," one intern lamented.

Training and development opportunities were often offered to permanent staff only. As a result, many interns were excluded from such capacity building activities, which help prepare staff for management positions. After the internship, some graduates were retained as contract workers, which still prevented them from participating in staff development and management training programmes.

While the focus groups were conducted in the twelfth month of the year-long internships, only $27 \%(4 / 15)$ had received written confirmation of permanent employment from their host. All of them were in the smaller retail group, which had recently undergone restructuring and retrenched some employees. The rest remained uncertain while desperately applying for any job - as security guards, call centre agents, receptionists, or anything that would rescue them from impending unemployment. Even though many had gone for interviews across the sector in general, none of them had been called back for a second interview. After a yearlong internship, the participants reported that they were frequently told that they did not have sufficient work experience. Most companies require at least three years' work experience for permanent entry-level positions. For more senior management positions, they require a minimum of 10 years' experience. 
Finally, interns lamented that the internship programme administrators could not make time to visit some of the internship sites. At one site, an officer came only once near the end of the internship. While the visit was informative for the interns, they felt they could have benefitted more had they been visited earlier. They needed the SETA to see their working conditions and monitor their adjustment to the work environment, i.e. to show that it cared about their professional growth and wellbeing and was not just "throwing money" at them.

\subsection{Absorption Rates}

This was the first survey of its kind and was met with a lot of suspicion and even hostility by some employers who had never been asked questions about their interns before. Because many host companies have no internship policies, dedicated internship management personnel, or tracking mechanisms for capturing the information we requested, our attempts to collect accurate data were greatly compromised. Companies reported figures for varying periods, e.g. ten, two or five years, depending on the duration of their participation between 2004 and 2016. As a result, the numbers we present reflect both genders but are only approximates at best, as some entities reported the total number of black interns who participated (including those who resigned or were dismissed), while others reported only those who completed the internship. Similar inaccuracies are present in the absorption rates. Some companies reported only on the number of interns who were absorbed by the company. Others reported the total number including those who had been offered but had not accepted, a job. The total number of interns who were absorbed or offered jobs also does not distinguish between the types of jobs offered, e.g. permanent or short-term contracts. From the respondents 1427 out of 4503 interns were absorbed or offered jobs by their hosts between 2004 and 2016. This reflects a 32\% absorption rate, which is less than the $60 \%$ estimated by the W\&RSETA. We can assume that at the end of their tenure, many of the interns get absorbed in other sectors since graduates generally have a better change of obtaining employment than job seekers with only a Grade 12 certificate. The core skills interns learn in retail are often also relevant in other sectors.

\subsection{Career Progression}

This section highlights the perceived value of the internship as evidenced by the perceptions and subsequent experiences of the four young black male managers who completed the programme some years back. While the internship experience is different for everyone, career progress is a prominent marker of the success of internship programmes. Increased progression in one's career is evidenced by significant increases in any combination of the following: compensation, level of responsibility, rate of advancement, and job satisfaction.

Individuals employed as retail managers display progress in their careers by moving beyond the management trainee level. While this promotion can occur during the tenure of the internship in exceptional cases, for these four it occurred at least three years after securing permanent employment. For example, one former intern became a store manager of 68 employees after working in a family-owned store for three years. Another who was in the internship programme in 2008 gradually made his way up to be an HR Training Manager after five years. In 2016 he was promoted to be an HR manager of more than 500 employees in a new store that the wholesale chain was about to open in Gauteng. In his new role he would report to the regional manager. He was encouraged by the fact that all the HR Directors in this wholesale chain are black and felt he had plenty of role models across the country.

For many people compensation is an important measure of career progress. To provide some measure of success in this regard, an example is provided by another manager who also interned in 2008 and was, by 2016, a Regional HR Manager of a big retail chain. His annual salary package was R460, 000 $(\$ 29,490)$ including a 13th cheque and a performance bonus. Although he was very committed to the organisation, he bemoaned the fact that he would never be promoted to be a Divisional Head, because everybody at the very top is white. In his organisation, the positions of Divisional Heads are never advertised. He believes that white men just appoint each other. It did not help him that the Divisional Head he reported to be a younger white male with less experience and would probably stay for decades before he retires. A manager who had interned in 2009 had gradually had his annual salary package 
increased to R420, 000 (\$26,920) including a car allowance, car insurance, and subsidised medical and retirement insurance.

"The internship helped me make the transition. Unlike at varsity, in corporate (sic) $65 \%$ doesn't determine your passing. The company expects $100 \%$ output and accuracy all the time, even on Public Holidays," one manager observed. This perceptive remark sums up how the graduates felt they had grown because of the internship by learning the important skills of leadership, supervision, human relations, communication, decision-making, and problem solving.

Another finding is that increasing the cohort of interns who become managers can help improve the working conditions for interns. For example, one of the successful managers mentioned above asserted that because he had been a SETA intern, he had a better appreciation of how best to treat the interns in the store he managed. He did not recruit more interns than he needed. He also excused interns from coming to work on weekend, because he knew that depleted their stipends.

Despite the obvious challenges, all four managers believed that with hard work, passion and commitment, many black people can succeed in retail. Their advice to current interns was they should continue to believe in themselves and to take advantage of every opportunity they are given to advance their careers.

\section{Implications and recommendations}

The implications of the above findings are that while the stipend enables socio-economically disadvantaged graduates to participate in the programme, R3, 500 (\$220) per month is not enough in the current economy. The amount might have sufficed eight years ago but its value has in fact declined over time in real terms - it is now about equal to the national minimum wage of R20/hour ( $\$ 1.30 /$ hour). Food, rent, public transport (to work and interviews) and telecommunication costs are high, and those interns who do not live with their parents admitted that they almost must go without food towards the end of the month. The stipend therefore needs to be reviewed and increased appropriately for these graduates.

Interns felt exploited when they were not fairly compensated for performing work for which fulltime employees were paid wages. If interns work longer than the stipulated time, especially during peak times, then they must earn more for the overtime. Host employers should top-up the SETA's stipend where necessary.

Regarding job characteristics, while administering an internship programme might be time consuming, it is imperative that the retailers meet and sustain requisite criteria for delivering a highquality internship programme. This includes ensuring the programme is aligned with the company's strategic objectives and is well structured (properly planned). Secondly, interns should undergo a basic induction programme to acclimatise them to the organisation's culture as quickly as possible and to manage their expectations about permanent placements. Job descriptions and responsibilities should be clarified, and designated mentors should be trained to give constructive feedback for specific projects that interns execute. The responsibility of managing interns should be reserved for people who see themselves as change agents, counsellors, and coaches, hence the obligation to engage with the interns regularly. Mentors should be incentivised and compensated for their efforts to ensure both the professional and personal growth of their interns. Moreover, all permanent employees must be informed of the role of the internship programme beforehand. Finally, interns whose appointments will be converted to full-time employment should be advised in good time to minimise uncertainty and anxiety.

Given the high rate of youth unemployment in South Africa, it is tempting for retailers to take on more interns than they have positions for, if only to get them out of the ever-increasing pool of unemployed black graduates, help them earn some income, and expose them to the work environment. The negative effects of such benevolence are that the interns get demoralised and feel humiliated if they come to work but have nothing to do. Young people are eager to learn new things and get bored if not fully engaged. We, therefore, strongly recommend that retailers grow their internship programmes carefully and organically as the company expands.

A fifth of the focus group participants expressed a keen desire to pursue post-graduate studies, yet none was aware of the post-graduate funding that the SETA provides. Extensive sectoral communication in this regard is critical. This is a self-selected, and therefore ambitious, cohort of potential 
academics and researchers. The SETA should nurture them to improve the skills and demographic composition of educators in the retail departments of higher education institutions.

Close observation and active participation has given the entrepreneurial interns the "know-how" and confidence to become retailers. For those interns who saw themselves as business owners in five years, the SETA should take a proactive role to ensure these aspirations are realised. For example, it should explore synergies with government's small business development agencies, incubation programmes, and franchise associations to enable entrepreneurial interns to set up their businesses under the umbrellas of these long-established and well-structured entities. Considering the drive to professionalise the sector and to formalise informal businesses, the advancement of these future business leaders should be prioritised as they can help reduce youth (15-34 years) unemployment, currently very high at $38.6 \%$ (StatsSA, 2017).

Given the strong potential that the internship programme must contribute to skills development and transformation in the sector, and to South Africa in general, it is critical that the administration of the programme becomes robust to meet the needs of all the stakeholders. Such a programme ought to be implemented and monitored by dedicated and competent programme officers who have the funds, personnel, and expertise to meet the programme's administrative demands. Whether these are centralised at the head office to ensure uniformity and better accountability or decentralised to the provincial offices to allow for better localised monitoring, faster disbursement of funds, and better overall responsiveness, is for the SETA to decide.

To drive a more rigorous internship programme, the SETA should stratify the host employers into two somewhat distinct groups: the large wholesalers and retailers that provide the workplace experience and training opportunities for the interns and the smaller retailers who employ them permanently. Large retailers have better-structured internship systems and dedicated talent management or learning and development practitioners. They can provide both room for rotation among different units and focussed, singular projects that must be rolled out in a big corporation. With regards to skills training and development, those retailers who have sufficient budgets must allow interns to partake in the management development programmes that are usually reserved for full-time managers, in case they are appointed full-time later. Even if they are not appointed by the retailer who pays for their managerial training and development, the big retailers and wholesalers should provide such capacity building as their contribution to creating a better skilled and more diversified retail workforce for the future. Wellcoordinated interventions would have a better impact in an economy that is still developing.

Given the size of the task, the SETA should capitalise on the existing technological advances to improve both its efficiency in its administrative processes and its communication with all its stakeholders. For example, instead of expecting retailers to source the interns themselves, much value would be derived from the SETA using a digital platform open to the sector. Such a platform could allow for online advertising and placements, and for the use of bulk short messaging systems (SMSs). This is important as many graduates now have cell phones or android devices with which to access the Internet. Maximising the use of technology can assist the SETA to capture accurate data, monitor and evaluate, and produce efficient reports or mechanisms to keep track of the interns long after their tenure. All these processes ought to be user-friendly and seamless.

The total participation of wholesalers and retailers is very low for such a large and vibrant sector. To only have 38 companies hosting interns in the three most economically active provinces is dismal, considering that Sandton City Mall alone, which is one of more than 80 malls in the greater Johannesburg area, has more than 300 stores. Currently, the most active trade categories are food and groceries as well as clothing and footwear. It is imperative that all trade categories are mobilised to get more involved in this intervention. As retailers have already paid towards the sector's skills development levies by providing monies for bursaries and internships, these resources must not go to waste. The SETA must campaign tirelessly to exponentially increase the number of interns and host employers.

\section{Conclusion}

Our study sought to investigate how the internship programme has provided a useful tool for skills development in the W\&R sector. We therefore sought to provide measurements (quantitative and 
qualitative) for the internships' impact on job acquisition and socio-economic transformation by identifying and describing the factors that have influenced its successes or challenges.

Our findings are that the programme is very beneficial to the participants, as they get exposure to real work opportunities that help combine the classroom theory with practical experiences. The fact that blacks and women participate, contributes meaningfully towards empowering the previously disadvantaged with requisite skills for the sector. Their demographic representativeness should also increase over time. The internship programme thus has immense potential to play a very enabling role in transforming retail graduates from being unemployed to being knowledgeable, experienced employees with the potential to ultimately become professional senior retail executives. We also found that previous interns perceived the value of the internship as being positive, as shown by their career progression and trajectory towards upward social mobility and better pay. Therefore, while the small sample size is a notable limitation of this study, its findings might have relevance for other sector sponsored internship programmes.

To improve the intervention in the future, we highlighted the need for the SETA's administrators to strengthen partnerships with their key stakeholders, to effectively communicate their transformative skills development agenda, and to optimise administrative efficiency by using relevant information technology systems.

\section{Limitations of the research}

The case study method, based on a small, convenience sample related to a single intervention, indicates that generalisation should be done with great care. A further limitation is that respondents came from only 12 retailers - obviously not a representative sample of the South African retail sector. However, as this was an exploratory study and as the objective was to better understand the benefits, weaknesses and implementation of internships, these limitations do not undermine the value of the findings presented. Furthermore, the sample of 12 retailers, although small, was adequate for an exploratory study as they all were involved in, and knowledgeable about, the internship programme.

To overcome these limitations, and to be able to generalise these findings, a larger, quantitative study (possibly including a longitudinal study with pre and post-testing of interns' skill sets and career progression) is recommended.

\section{Future Research}

In addition to the recommendation above for a larger, quantitative study, the most important recommendation for future research is the need to fill the void in the knowledge base related to medium and longer-term impacts of retail internships. Issues that could benefit from further research could include:

- How does the compensation of black managers who were interns compare with that of their white counterparts who did not enter the industry via the internship programme?

- It would also be useful to see if age is a factor in compensation growth, as more executives will hold qualifications instead of receiving promotions by working their way slowly up through the store ranks. In other words, will younger individuals advance faster than older individuals do over time, since they have more energy, will have more qualifications, will be digital natives, and their life situations allow more flexibility to relocate or work unusual hours?

- What will be the effects of more women professionals on the "glass ceiling'?

\section{References}

Blom, R. (2013). A policy framework for work-integrated learning. The African Journal for Work-Based Learning, 2(1), 112.

Buhlungu, S. \& Metcalfe, A. (2001). Breaking the Racial Division of Labour Knowledge Production: Reflection on Internship Programmes. Perspectives in Education 19(2): 67-84.

Burns, C. \& Chopra, S. (2017). A meta-analysis of the effect of industry engagement on student learning in undergraduate programs. Journal of Technology, Management, and Applied Engineering 33 (1): 1 - 10.

Frenette, A. (2013). Making the Intern Economy: Role and Career Challenges of the Music Industry Intern. Work and Occupation 40 (4): $364-397$. 
Goodenough, A., Roberts, H., Biggs, D., Derounian, J. Hart, A. \& Lynch, K. (2017). More resilience: Using psychometric testing to reveal the benefits of university internship placements. Active Learning in Higher Education. In press. https://doi.org/10.1177/1469787417747057

Govender, C. \& Taylor, S. (2015). A Work Integrated Learning Partnership Model for Higher Education Graduates to Gain Employment. South African Review of Sociology, 46 (2), 43-59.

Grayson, D. (2012). Evaluation of the National Youth Service Programme of the Department of Science and Technology. Retrieved from: www.nstf.org.za/youth/NYSreport.pdf

Green, R. \& Farazmand, F. (2012). Experiential Learning: the internship and live-case study relationship. Business Education and Accreditation, 4(1), 13-23.

Guile, D. (2009). Conceptualising the Transition from Education to Work as Vocational Practice: Lessons from the UK's Creative and Cultural Sector. British Educational Research Journal 35 (5): 761 - 779.

Guile, D \& Lahiff, A. (2013). Internship: Conventional Wisdom, Models and Recommendations. London: CET and Institute of Education, University of London.

High Fliers. (2014). The Graduate Market in 2014. Retrieved from: www.highfliers.co.za/download/2014/GMReview14.pdf

Hurst, J, Good, L. \& Gardner, P. (2012). Conversion Intentions of Interns: What are the Motivating Factors? Education and Training 54 (6): $504-522$.

iEducation SETA South Africa. (n.d.). Skills Education Training Authorities in South Africa. Retrieved from: www.vocational.co.za/

Jackson, D. (2015). Employability Skill Development in Work-Integrated Learning: Barriers and Best Practice. Studies in Higher Education 40(2), 350-67.

Jackson, D., Rowbottom, D., Ferns, S. \& McLaren, D. (2017). Employer understanding of Work-Integrated Learning and the challenges of engaging in work placement opportunities. Studies in Continuing Education 39 (1) 35-51.

Klein, M. \& Weiss, F. (2011). Is forcing them worth the effort? Benefits of mandatory internships for graduates from diverse family backgrounds at labour market entry. Studies Higher Education, 36(8), 969-987.

Koyana, S. (2014). Final Report on the Internship Baseline Study 2013. National Youth Development Agency.

Retrieved from:

https: / / www.google.com/url?sat\&rct=j\&q=\&esrc=s\&source=web\&cd=1\&ved=0ahUKEwjoi9jdiu7YAhXrDcA KHbEQBf0QFggrMAA\&url=http\%3A\%2F\%2Fwww.nyda.gov.za\%2FPublications \%2FPublications \%2FFinal \%2 520Report\%2520for\%2520SAGDA\%2520revised\%252028_03_2014_Print.pdf\&usg=AOvVaw2muP6pgqCdQNB Z-9xLKQOd.

Mabiza, J., Mahlalela, P. \& Mbohwa, C. (2017). Reducing Unemployment Rate in South Africa through Establishment of Graduate Internship Programmes (GIP). Proceedings of the International MultiConference of Engineers and Computer Scientists 2017, Vol II, March 15-17, Hong Kong.

McHugh, P. (2017). The impact of compensation, supervision and work design on internship efficacy: implications for educators, employers and prospective interns. Journal of Education and Work. 30 (4): 367 -382.

Meinert, D. (2013). Fresh Faces: A Well-planned Internship Program Can Energize Your Enterprise. HR Magazine 58 (11): $25-28$.

O'Connor, H. \& Bodicoat, M. (2017. Exploitation or Opportunity? Student Perceptions of Internships in Enhancing Employability Skills. British Journal of Sociology and Education. 38(4), 435-449.

Pop, A. (2010). A National Skills Development Graduate Programme as a Talent Retention Strategy. M.B.A. thesis, GIBS, Pretoria, University of Pretoria.

Pop, C. \& Barkhuizen, N. (2010). The Relationship between Skills Training and Retention of Graduate Interns in a South Africa Information, Communication and Technology Company. Literacy Information and Computer Education Journal (LICEJ), 1(2), June 75-83.

Pop, C. \& Barkhuizen, N. (2013). Exploring the effectiveness of a work-integrated learning programme in contributing towards the employability of graduates: the graduate interns' perspective. African Journal for Work-Based Learning, 1(1), 28-38.

Republic of South Africa, Department of Higher Education and Training. (2013). White Paper for Post- School Education and Training. Pretoria. Retrieved from: www.dhet.gov.za/SiteAssets/Latest \%20News/White\%20paper\%20for\%20postschool\%20education \%20and\%20training.pdf.

Republic of South Africa, Department of the Presidency. (2011). National Development Plan 2030: Our future - make it work. Pretoria. Retrieved from: www.gov.za/documents/national-development-plan-2030-our-future-makeit-work.

Sewell, W., Mason, R.B. \& Venter, P. (2014). Strategy Alignment of the SA Retail Sector with the National Development Plan: Vision 2030. Journal of Governance and Regulation, 3(4), 235-251 
Silva, P. Lopes, B., Costa, M., Melo, A.I., Dias, G.P., Brito, E. \& Seabra, D. (2018). The million-dollar question: can internships boost employment? Studies in Higher Education, 43(1), 2-21.

Simons. L., Fehr, L. \& Blank, N. (2012). Lessons Learned from Experiential Learning: What Do Students Learn from a Practicum/Internship? International Journal of Teaching and Learning in Higher Education, 24(3), 325-334.

Smith, C., \& Worsfold, K. (2014). WIL curriculum design and student learning: a structural model of their effects on student satisfaction. Studies in Higher Education 39 (6): 1070-1084.

South African Market Insights (2015). South Africa's Economic Structure from 1994 to 2015. Retrieved from:

https://www.southafricanmi.com/southafrica.html

StatsSA. (2017). Quarterly Labour Force Survey (QLFS) of Statistics South Africa. Retrieved from: www.statssa.gov.za/?p=9960.

Suen, S. \& Brandeisky, K. (2014). Tracking Intern Lawsuits. ProPublica. Retrieved from:

https:// projects.propublica.org/graphics/intern-suits

Surujlal, J. \& Singh, C. (2009). Internship as a Mechanism for the Preparation of Sports Management Personnel. African Journal for Physical Health Education, Recreation, and Dance, Supplement 1: 204-219.

Virtanen, A., Tynjälä, P. \& Eteläpelto, A. (2014). Factors Promoting Vocational Students' Learning at Work: Study on Student Experiences. Journal of Education and Work 27 (1): 43-70.

Wolbers, M. (2003). Job mismatches and their labour-market effects among school-leavers in Europe. European Sociological Review 19(3), 249-66.

W\&RSETA. (2012). Sector Skills Plan 2011-2016: 2012 update. Retrieved from: www.wrseta.org.za/downloads/WRSETA_Updated_Draft_SSP_2011-2016.pdf

W\&RSETA. (2014). Wholesale \& Retail Sector Education and Training Authority (W\&RSETA) Sector Skills Plan 20112016, 2014 Update. W\&RSETA: Centurion.

W\&RSETA. (2016). Sector Skills Plan 2016-2017 Final. 1 August. Retrieved from: www.wrseta.org.za/downloads/2016-17 WRSETA Sector Skills Plan.pdf 